\title{
Characterization of Collected Wood Combustion Nanoparticulates from the Gas Stream of Pellet and Wood Chip Stoves
}

\author{
B. Panessa-Warren ${ }^{1}$, T. Butcher ${ }^{2}$, J. Warren ${ }^{1}$, R. Trojanowski ${ }^{2}$, K. Kisslinger ${ }^{3}$, G. Wei $^{2}$, Y. Celebi $^{2}$ \\ 1. Instrumentation Division, Brookhaven National Laboratory, Upton, NY, USA \\ 2. Dept. of Renewable Energy Sciences, Brookhaven National Laboratory, Upton, NY, USA \\ 3. Center for Functional Nanomaterials, Brookhaven National Laboratory, Upton, NY, USA
}

The use of wood-burning boilers and stoves globally has increased the amount and types of wood combustion nanoparticle emissions released into populated areas and the environment. This study utilized high resolution transmission and scanning electron microscopy (HRTEM/HRSEM) to morphologically characterize nanoparticles produced/released at specific times in the burn cycle from 7 wood-pellet boilers and 3 wood-chip boilers. We characterized the elemental composition and crystallinity of nano-salt crystals, graphene and graphite nanoparticle emissions produced, during specific phases in the burn cycle. Combustion emission nanoparticles were collected from the gas stream (within the dilution tunnel) during 4 phases of each burn cycle. Nanoparticles were morphologically and elementally characterized by HRTEM/HRSEM. By correlating nanoparticle structure and composition to the recorded combustion conditions $\left(\mathrm{O}_{2}, \mathrm{CO}_{2}, \mathrm{CO}\right.$ gas levels; fuel type and load; the use of advanced technology auto-regulation; and catalysts) for the 6 pellet stoves and 3 wood chip stoves tested, the data revealed that the wood boilers/stoves produced different types, and compositions, of nanoparticles based on wood fuel type and quality, burner operating conditions during specific stages of the burn cycle, and the use of advanced technology designs with autoregulation of air, fuel delivery, catalyst use, as well as automatic shut-down and re-fire.

Samples were collected at the Brookhaven National Laboratory facility developed by Dr. Tom Butcher using his Biomass Combustion Test Method, which permitted constant recording of the combustion gases, fuel load, temperatures in the: stack, dilution tunnel, and upper stack during the entire trial for each wood combustion stove tested. Different fuels were used to evaluate how wood type, moisture and cleanliness effected combustion emissions. Southern and northern hardwood pellets and chips, cleaned maple wood chips, and higher quality, pre-cleaned hardwood pellets were tested. Nanoparticles (NPs)were harvested from the gas stream at steady state, late steady state, smolder and burnout phases. All samples were stored immediately in desiccators and analyzed using HRTEM, SAED and x-ray microanalysis, as well as high resolution field emission SEM with SDD flash x-ray microanalysis. This data was then correlated with the temperature, gas and operating conditions used for each sampling session, to determine how nanoparticle type and composition was altered by specific operating conditions, engineering advances (catalysts) and fuel quality/type at specific phases of the burn cycle.

Nanoparticle collection was repeated 3-4 times, and the nanoparticles were characterized for each burn cycle phase. This characterization was done using a JEOL 2100 field emission (200KV) TEM equipped with STEM, selected area electron diffraction (SAED) and an Oxford EDS system; a JEOL 1400 LaB6 $(120 \mathrm{KV})$ analytical TEM equipped with EDAX x-ray microanalysis and SAED systems; and a JEOL 6500F field emission SEM equipped with a Bruker $403030 \mathrm{~mm}^{2}$ Silicon Drift Detector (SDD) for rapid $\mathrm{x}$-ray microanalysis.

Reduced soot and production of carbon NPs were observed when no bark, clean, low moisture, southern/northern hardwood pellets or wood chips, and washed Maplewood chips, were used in the modern wood-pellet and wood-chip boilers/stoves. The most reduced NPs emissions, with no carbon 
spherule chains evident, were obtained using washed Maple chip fuel. The reduction of moisture, in the pellets and chips, correlated with reduced formation of graphene/graphitic chains, and nano-salt emissions. The nano-salts produced from the cleaned pellet and wood chip fuels (with no bark), produced predominately nano-salt crystals with $\mathrm{K}, \mathrm{Na}$ or $\mathrm{Ca}$ salts, with no evidence of potentially toxic metals ( $\mathrm{Al}, \mathrm{Mg}, \mathrm{Ti}, \mathrm{Pb}, \mathrm{Cr}, \mathrm{Fe}, \mathrm{Zn}$ and $\mathrm{Sn}$ ) seen when cordwood or pellet fuel with bark was used.

The advanced technology designs of the pellet and wood chip stoves/boilers, included automatic control systems and catalysts, which significantly reduced carbon emissions, produced low Z salt crystals (containing $\mathrm{Na}, \mathrm{Ca}, \mathrm{K}, \mathrm{Cl}$, with reduced $\mathrm{C}, \mathrm{S}$ and $\mathrm{O}_{2}$ ), and over-all a reduction in nanoparticle emissions. Collectively this can reduce environmental contamination and respiratory risks. Some of the wood chip and pellet systems tested, produced no carbon in the NP emissions during mid-steady state to burn-out, when clean, high quality fuel, and operating conditions were optimized [1].

References:

[1] This research used resources of the Center for Functional Nanomaterials, a U.S. DOE Office of Science Facility, at Brookhaven National Laboratory under Contract No. DE-SC0012704.This study was funded by the New York State Energy Research and Development Authority agreement number 63038.

Figure 1. Pellet Stove. The low magnification of the capture grid surface shows groups of small NPs around the rims of circular ( $2 \mu \mathrm{m}$ diam.) holes on the capture membrane. Two large black 4-8 $\mu \mathrm{m}$ aggregates of incompletely burned wood fibers revealed high $\mathrm{Si}$, metals, organics and salt crystals. These incomplete combustion aggregates produce environmental contamination.

Fig. 1.
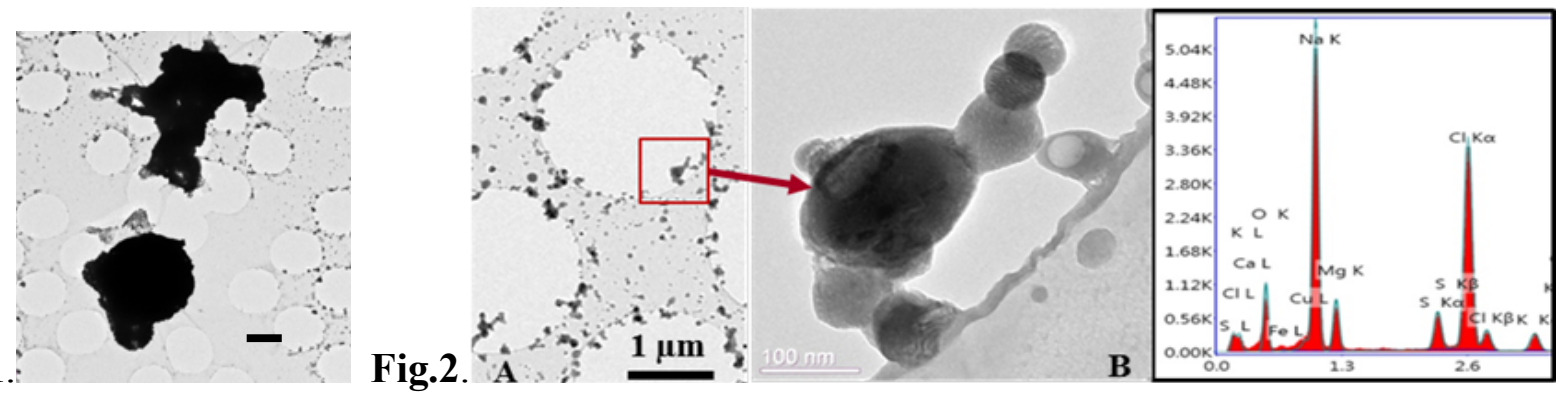

Figure 2. NPs and NP-aggregates from advanced technology pellet stove (high quality hardwood pellets), showed spherical combustion nanoparticles (A), joined into chains (B). A small chain of joined combustion spherules, attached to the edge of a circular opening $(\mathbf{B})$, when analyzed revealed no carbon, very low nanoparticle production and no evidence of environmentally toxic elements.
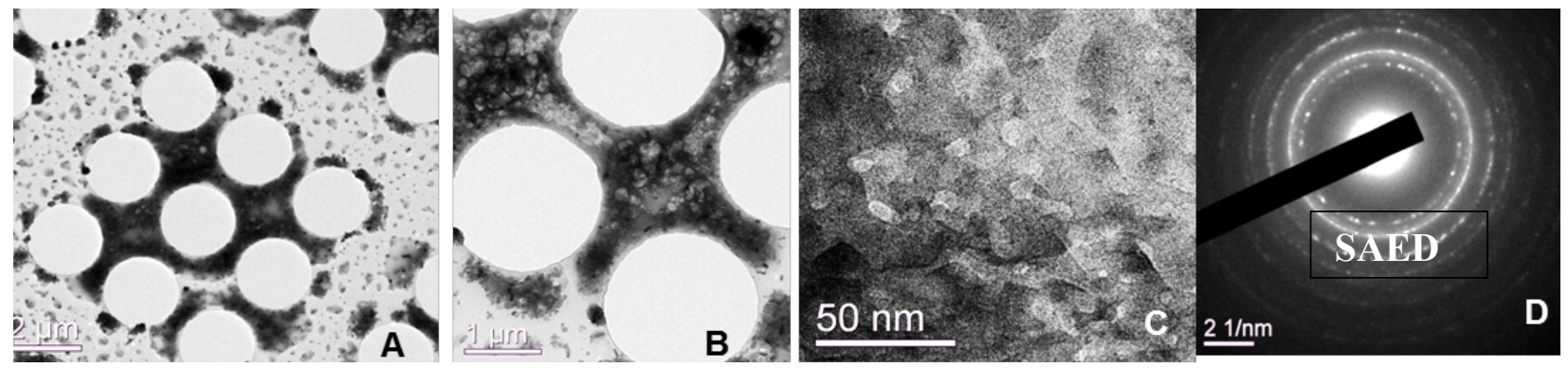

Figure 3. Poorer quality wood chips produced large amounts of carbon and salt deposits on the capture membrane (3A). At higher magnification crystal formation between the circular holes (Fig.3B, 3C) was visible even at this early stage. SAED verified high salt concentration, and some soft carbon rings. 